\title{
Performance analysis of new structure heat exchanger based on field synergy and numerical simulation
}

\author{
Xinpu Song ${ }^{1}$, Feng Zhang ${ }^{2}$, Jin $\mathrm{Yu}^{1}$, Dongsheng $\mathrm{Xi}^{3}$, and Mengdi Chen ${ }^{3, *}$ \\ ${ }^{1}$ State Grid Xinjiang Economic Research Institute, 83000, Urumqi, China \\ ${ }^{2}$ State Grid Xinjiang Electric Power Co., Ltd, 83000, Urumqi, China \\ ${ }^{3}$ Beijing Smart China Energy Internet Research Institute, 100176, Beijing, China
}

\begin{abstract}
High efficiency heat exchanger is always a hot topic, and field synergy theory is introduced as an important means to optimize the heat transfer efficiency. Based on the field synergy theory, a new type of heat exchanger is proposed in this paper, in which, the cold and hot fluid presents reverse cross flow law. Through the verification of the test and numerical simulation results, a reasonable numerical simulation model and method are obtained. Then, the flow and heat transfer conditions of the new structure heat exchanger are simulated by the verified numerical simulation technology. The conclusion is as follows: K- $\varepsilon$ turbulence model and coupled heat transfer model can be effectively used in the numerical simulation of heat exchanger. And the reverse cross convection heat exchanger can effectively improve the uniformity of water temperature distribution in the heat exchanger.
\end{abstract}

\section{Introduction}

The effective utilization of energy has always been accompanied by the development of human society. Since the discovery of fire, the discussion and research on energy utilization has continued up to now, such as the efficient combustion and power generation of fossil fuels, the efficient conversion and transfer of heat energy, etc ${ }^{1}$. The process of energy utilization mainly includes two aspects, one is the transformation of energy, and the other is the transfer of energy ${ }^{2}$. It is also one of the main equipment to improve energy utilization efficiency. The heat exchanger industry involves nearly 30 kinds of industries, such as HVAC, pressure vessel, reclaimed water treatment equipment, chemical industry, petroleum, etc ${ }^{3}$.

There are many kinds of heat exchangers, and there are many researches on them. Based on the field synergy theory, this paper proposes a new type of plate heat exchanger, which is based on the plate heat exchanger, adding a Z-shaped baffle on the plate surface of the heat exchanger to separate the hot and cold fluid on both sides of the baffle plate. At the same time, the numerical simulation technology is used to study the fluid flow, temperature distribution and efficiency of the heat exchanger.

\footnotetext{
*Corresponding author: 44095073@qq.com
} 


\section{Materials and models}

\subsection{Physical models}

The structure of the new heat exchanger is shown in Fig.1. This type of heat exchanger is optimized on the basis of plate heat exchanger. Reverse, interval and cross flow of cold and hot fluid in the heat exchanger. In Fig.1, the red area represents the hot fluid flow inlet area, the blue area represents the cold fluid inlet area, and the yellow area inside the heat exchanger is the cold and hot fluid separator. The fluid area of each layer of heat exchanger is divided into hot and cold fluid areas through baffles. The hot and cold fluid flows in opposite directions on both sides of the "Z" baffles.

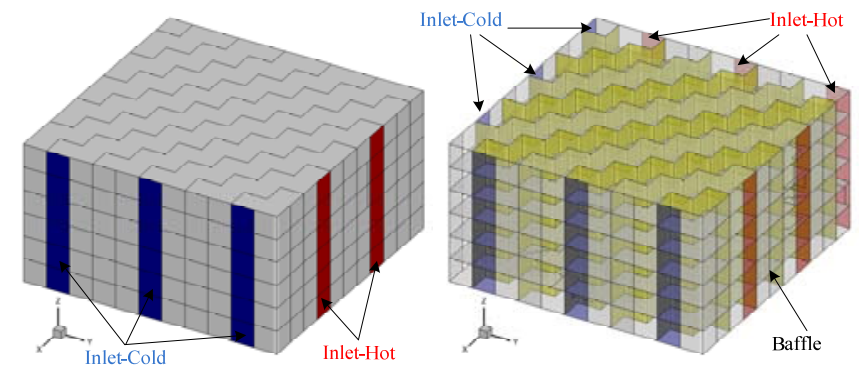

Fig. 1. The structure of heat exchanger

\subsection{Mathematical models}

When the fluid flows in the heat exchanger, a velocity boundary layer and a temperature boundary layer will be formed on the wall of the heat exchanger, and a mass boundary layer will be formed on the wall when there is mass exchange of the fluid ${ }^{4}$. When CFD numerical simulation technology is used to analyze the flow and heat transfer characteristics inside the heat exchanger, the governing equations can be written as the following equation ${ }^{5-7}$ :

$$
\frac{\partial(\rho \phi)}{\partial t}+\operatorname{div}(\rho v \phi)=\operatorname{div}\left(\Gamma_{\phi} \operatorname{grad} \phi\right)+S_{\phi}
$$

In this equation, the above parameters can be found in reference ${ }^{7}$.

Table 1. Parameters of the governing equations

\begin{tabular}{cccc}
\hline & $\phi$ & $\Gamma_{\phi}$ & $S_{\phi}$ \\
\hline Continuity & 1 & 0 & 0 \\
Momentum & $v_{i}$ & $\mu$ & $-\frac{\partial p}{\partial x_{i}}+S_{i}$ \\
Energy & $T$ & $\frac{k}{c_{p}}$ & $\frac{S_{T}}{c_{p}}$ \\
Component & $m_{l}$ & $D_{l}$ & $S_{l}$ \\
\hline
\end{tabular}




\section{Numerical simulation verification and analysis}

In the numerical process, different mathematical models and boundary conditions were chosen to simulate the operation characteristics of the heat exchanger under different conditions. In order to ensure the accuracy and reliability of numerical simulation, this paper selects the comparison of experimental data and simulation data in the literature ${ }^{8}$ to verify the reliability of numerical simulation results. The comparison results of experiment and numerical simulation are shown in Fig.2.

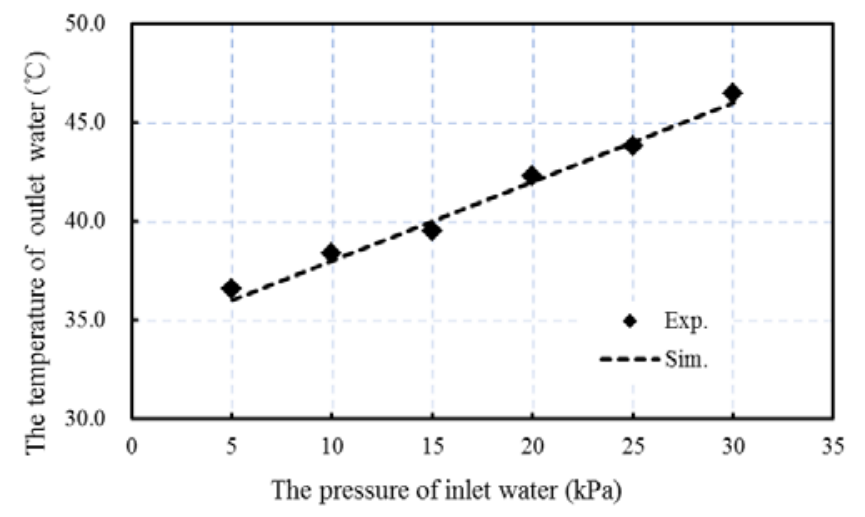

Fig. 2. The comparison of the experiment and numerical simulation results

A comparison between experimental and simulation results are shown in Fig.5. Relative errors falls within $\pm 5 \%$. The results of the numerical model agree well with those of the experiments.

\section{Results and discussion}

Firstly, the flow inlet speed of $3.0 \mathrm{~m} / \mathrm{s}$, high-temperature flow inlet temperature of $75{ }^{\circ} \mathrm{C}$, and low-temperature flow inlet temperature of $25{ }^{\circ} \mathrm{C}$ are analyzed; the temperature distribution in the internal fluid flow channel of the heat exchanger is shown in Fig.3.
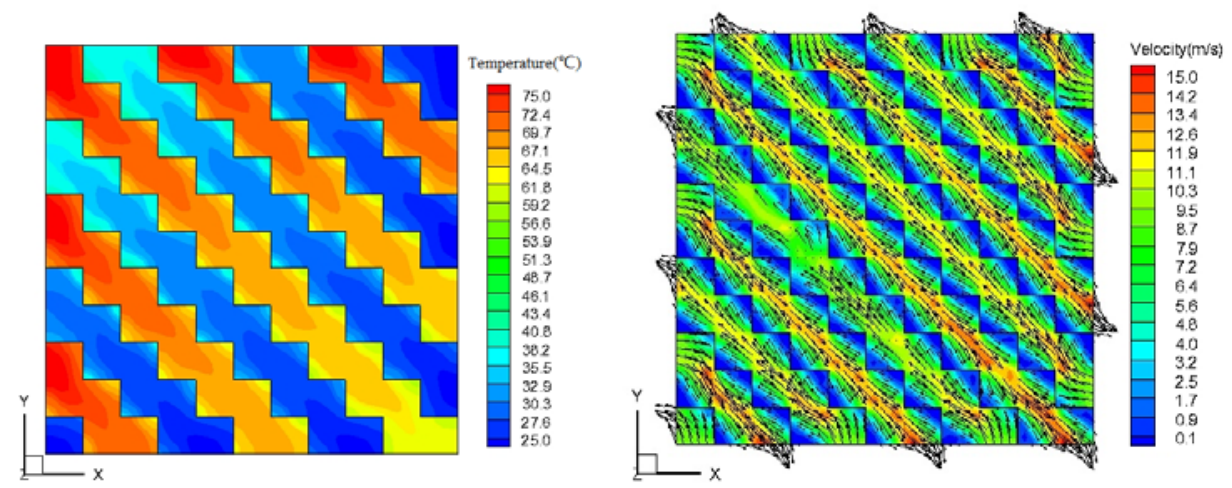

Fig. 3. Temperature and velocity distribution of water flow in heat exchanger

Fig.6 shows the temperature distribution of the central interface in the $\mathrm{Z}$ direction of the heat exchanger when the inlet temperature of the high and low temperature water flow is $75^{\circ} \mathrm{C}$ and $25^{\circ} \mathrm{C}$ respectively, and the inlet water flow speed is $3 \mathrm{~m} / \mathrm{s}$. It can be seen that in the heat exchanger, the hot and cold water flow through the heat exchange wall from both 
sides in reverse direction. The water flow path at the diagonal position is longer, and the heat exchange is more sufficient, while the heat exchange area away from the diagonal is smaller, which leads to the weakening of the heat exchange effect.

Similarly, the velocity distribution in the fluid flow channel of the heat exchanger under the same working condition is shown in Fig.6. It can be seen that in the heat exchanger, the water flow presents the rule of counter current cross flow, and the high and low temperature water flows in opposite intervals. The high-temperature water or low-temperature water is vertically incident to the inside of the heat exchanger from the inlet. After the jet flows to the first heat exchange wall, change the direction and enter the adjacent heat exchange space. Then change the direction on the heat exchange wall of the jet channel and continue until the water outflow. At the same time, the flow on the other side of the wall also shows the same law of motion. On both sides of the same heat transfer wall, the high and low temperature fluid presents the heat transfer condition of vertical jet, which can improve the heat transfer efficiency.
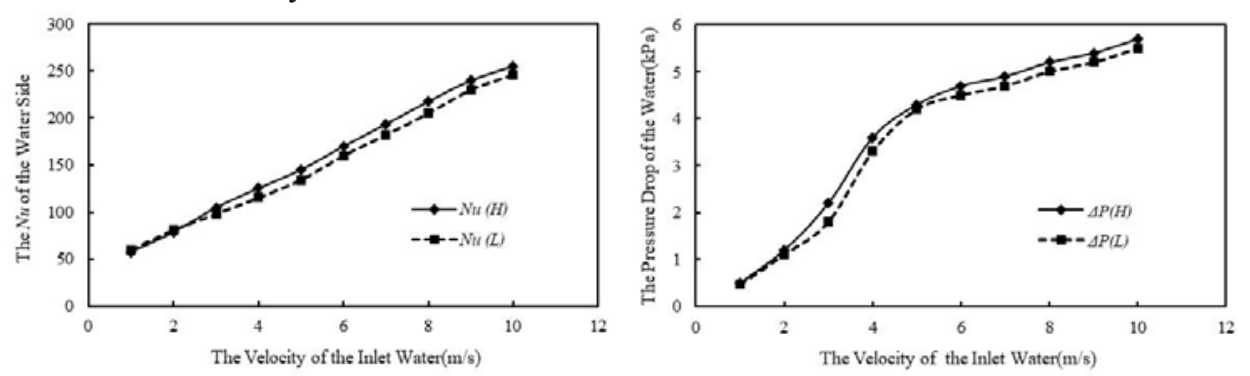

Fig. 4. The variation of $\mathrm{Nu}$ and velocity with flow inlet velocity in heat exchanger

Fig.4 shows the law that the number of $\mathrm{Nu}$ on the hot and cold water flow side changes with the inlet water flow speed. It can be seen that the number of $\mathrm{Nu}$ measured by the hot and cold water flow increases linearly with the increase of water flow. It can be seen that with the increase of water flow speed, the pressure drop of water flow increases gradually. This is mainly because with the increase of water flow speed, the turbulent energy consumption of water flow inside the heat exchanger increases, which increases the energy consumption of water flow.

Fig.9 shows the change rule of pressure drop of high and low temperature water inside the heat exchanger. It can be seen that with the increase of water flow speed, the pressure drop of water flow increases gradually. This is mainly because with the increase of water flow speed, the turbulent energy consumption of water flow inside the heat exchanger increases, which increases the energy consumption of water flow. It can also be seen that the overall pressure drop of hot water flow in the heat exchanger is higher than that of cold water flow, which is mainly related to the design of heat exchanger structure. Because of the different flow space of cold and hot water flow in the heat exchanger, the pressure drop of water flow in the heat exchanger is different.

There are two heat transfer interfaces within the heat exchanger. One is the heat transfer interface between the flue gas and gas channel wall surface, and the other is the heat transfer interface between the water and water channel wall. Therefore, there are two dimensionless $\mathrm{Nu}$ coefficients of heat convection written as follows:

$$
N u=\frac{h_{c} d_{0}}{\lambda}
$$

Where $h_{c}$ is the convective heat transfer coefficient, which can obtained by calculating the heat flux and temperature gradient at different locations within the heat exchanger. $d_{0}$ is 
the characteristic length of the heat transfer wall surface, and $\lambda$ is the heat conductivity coefficient of the heat exchange medium.

In the numerical simulation results, the overall thermal efficiency of the heat exchanger can be obtained by statistical calculation of the heat flow at the inlet and outlet of the cold and hot fluid. The thermal efficiency $\eta$ refers to the proportion of the heat obtained by cold water to the heat provided by hot water. In the heat exchanger of this structure, when the water flow inlet is $9 \mathrm{~m} / \mathrm{s}$, the heat efficiency of the heat exchanger reaches the highest value of $96 \%$, which is about $10 \%$ higher than that of traditional heat exchanger.

\section{Conclusion}

Based on the synergy theory of enhanced heat transfer field, a new structure of heat exchanger is proposed in this paper. The cold and hot fluid in the heat exchanger presents reverse cross flow law. A new type of reverse cross flow heat exchanger model is obtained by using the field synergy theory, and the K- $\varepsilon$ turbulence model is used for numerical simulation. Through the simulation and analysis of the temperature and velocity distribution in the heat exchanger, it is found that the heat exchanger can effectively improve the uniformity of the temperature distribution in the heat exchanger.

\section{References}

1. P. Sorknæs, H. Lund, I. R. Skov, S. Djørup, K. Skytte, P. E. Morthorst and F. Fausto, Renewable and Sustainable Energy Reviews, 2020, 119, 109655.

2. G. S. Jackson, L. Imponenti, K. J. Albrecht, D. C. Miller and R. J. Braun, Journal of Solar Energy Engineering, Transactions of the ASME, 2019, 141.

3. M. Mohanraj, S. Jayaraj and C. Muraleedharan, Int. J. Greenh. Gas Control, 2009, 3, 108-119.

4. M. M. Aslam Bhutta, N. Hayat, M. H. Bashir, A. R. Khan, K. N. Ahmad and S. Khan, Applied Thermal Engineering, 2012, 32, 1-12.

5. K. Elsayed and C. Lacor, Appl. Math. Model., 2013, 37, 5680-5704.

6. W. Cao and Y. Xue, Environmental Fluid Mechanics, 2017, 17, 1189-1205.

7. W.-x. Cao and X.-y. You, Powder Technol., 2017, 315, 282-289.

8. W. Cao, F. Liu and X. Y. You, Heat Mass Transfer, 2018, 54, 1951-1960. 